Schäfer, A.I. ; Broeckmann, A. ; Richards, B.S. (2005) Membranes and renewable energy — A new era of sustainable development for developing countries, Membrane Technology, Nov, 6-10.

\section{Membranes and Renewable Energy - A new Era of Sustainable Development for Developing Countries}

${ }^{1}$ Andrea I. Schäfer, ${ }^{1}$ Andreas Broeckmann and ${ }^{2}$ Bryce S. Richards

Environmental Engineering, University of Wollongong, Wollongong, NSW 2522, AUSTRALIA schaefer@uow.edu.au, ph +612 42213385, fax +61242214738
andreasb@uow.edu.au, ph +61 242213009 , fax +61 242213238

${ }^{2}$ Centre for Sustainable Energy Systems, Australian National University, Canberra, ACT 0200 AUSTRALIA bryce.richards@anu.edu.au ph++61 26125 9741, fax +61 261258873

\section{Abstract}

This article outlines the combination of a small scale hybrid ultrafiltration and nanofiltration/reverse osmosis system with solar energy. The system is targeted to remote communities with access to either contaminated surface or brackish water. The treatment accomplishes dual barrier disinfection, desalination, and removal of trace contaminants such as arsenic.

Investigation of the system is carried out for a variable power source that leads to fluctuations in feed flow and recovery. Those variations may affect water quality and fouling and to ensure satisfactory performance in locations far from qualified maintenance peronnel this information satisfactory performance in locations far from qualified maintenance personnel this information
needs to be integrated into process design and operation procedures.

The system exhibits a very low specific energy consumption and is able to desalinate brackish water to drinking water guidelines. Trace contaminant removal is under investigation and results are not presented in this paper.

Keywords: Desalination, Reverse Osmosis, Nanofiltration, Photovoltaic, Remote Community Water Supply

\section{The Need for a New Approach}

Access to a sufficient quantity of water of adequate quality for human consumption is a global problem. To date, traditional public health engineering and sanitation has contributed significantly in the developed world by achieving good separation of freshwater sources and wastewaters with a substantial infrastructure involving large distribution systems for drinking water provision and collection of sewage. However, these solutions alone are no longer sufficient. More recent trends include the consideration of water recycling as well as seawater desalination for drinking water provision, both involving rather advanced and energy intensive technologies such as membranes or advanced oxidation processes.

The approach remains one of solving problems with solutions that do not necessarily solve problems, but rather shift problems to other areas. In the case of seawater desalination two significant new problems are created (1) high energy consumption and (2) concentrate disposal. In the developed world those new problems are currently somewhat tolerated with further solutions pointing towards nuclear energy and concentrate treatment once environmental impacts of concentrate disposal (such as the often devastating effects on the marine environment [1]) can no longer be ignored. Alternatives such as sensible wate recycling, where the reduction in water consumption, reduction in marginally treated wastewater discharge and the impacts of energy intensive desalination can be avoided are often discarded too easily.

A drastic change of operations as proposed by Weber [2] in the existing circumstances is currently unlikely given the vast infrastructures involved, although some innovative ideas such as dual reticulation systems [3, 4] or decentralised treatment [5] are being implemented in selected new developments. The current situation leads necessarily to the underutilisation of readily available natural resources (such as solar energy in Australia) or the discharge of low salinity wastewater in preference for seawater as a water resource.

Developing countries provide an opportunity for innovation where basic infrastructure such as an electricity grid, potable water distribution and sewage collection systems are often unavailable. In those circumstances, the discussion of centralised versus decentralised treatment and renewable energy versus large scale power plants provide realistic opportunities for change. Further, given the circumstances, experience with technologies applied in developed countries is often vastly irrelevant an inappropriate. For example, where transport and communication infrastructure are also lacking, further challenges are posed for operation and maintenance.

In this article, a fully autonomous water desalination system using solar energy and membrane technology is described as an example of a new approach to water provision. The application of such systems is envisaged for remote villages for up to 200 people. The fourth prototype of this system is currently undergoing research and development to optimise performance and investigate socioeconomic integration, including system operation and maintenance.

\section{Small Treatment Systems combining Membranes and Solar Energy}

To address globally recognised lack of safe drinking water, partially caused by man-made pollution $[6,7]$ brackish and seawater is often used as a source for freshwater production. Due to the need of such systems for energy and the common unavailability of grid power in regions of concern, it is widely recognised that water filtration methods powered by renewable energy sources are required [8]. Over many years, water pumping systems powered by photovoltaic (PV) modules have proven to be extremely reliable, and are able to provide water in remote areas for the lowest costs [9]. Consequently, many examples of photovoltaic powered reverse osmosis (PV-RO) treatment systems can be found in the literature [9-17]. The successful adaptation of such systems to remote locations, where maintenance facilities are generally not available, is largely a question of robust system design and socio-economic integration.

The majority of PV-RO systems have been designed to operate at high pressures ( $>40$ bar) in order to desalinate seawater, often for off-shore applications. An overview of some 
Schäfer, A.I. ; Broeckmann, A. ; Richards, B.S. (2005) Membranes and renewable energy — A new era of sustainable development for developing countries, Membrane Technology, Nov, 6-10. doi:10.1016/S0958-2118(05)70569-3

PV-RO systems described in the literature, including various operating parameters and system performance is shown in Table 1.

Table 1: Overview of PV-RO units sorted by PV array size (adapted from [11])

\begin{tabular}{ccccccc}
\hline Location & $\begin{array}{c}\text { TDS Conc. } \\
\left(\mathbf{g} . \mathbf{L}^{-1}\right)\end{array}$ & $\begin{array}{c}\mathbf{P}_{\text {operate }} \\
(\mathbf{b a r})\end{array}$ & $\begin{array}{c}\text { Salt } \\
\text { Retention (\%) }\end{array}$ & $\begin{array}{c}\text { Recovery } \\
(\%)\end{array}$ & $\begin{array}{c}\text { Clean Water } \\
\left(\mathbf{m}^{3} . \mathbf{d}^{-1}\right)\end{array}$ & $\begin{array}{c}\text { SEC } \\
\left(\mathbf{k W . h} \cdot \mathbf{m}^{-3}\right)\end{array}$ \\
\hline Portugal & $2-5$ & 4 & 90 & 2 & 0.02 & 25.6 \\
Australia & 3.5 & $4-10$ & 92 & 10 & 0.1 & 8 \\
Australia & 5 & - & - & 16 or 25 & 0.4 & - \\
Canada & 33 & $34-35$ & $97-99$ & 14 & 0.85 & 4.0 \\
Australia & - & - & 88 & - & $0.4-1.0$ & $4.0-5.8$ \\
UK & 40 & $40-60$ & - & - & $3^{\dagger}$ & $3.5^{\dagger}$ \\
Mexico & Brackish & 40 & - & - & $0.7-1.4$ & $4.0-6.9$ \\
Oman & 1 & 12 & 96.6 & $65-70$ & 5 & 2.3 \\
Israel & 4 & $4-16$ & 98 & 50 & 3 & - \\
Spain & 35 & $45-70$ & $>98.5$ & - & $>0.8$ & $15-16$ \\
\hline
\end{tabular}

${ }^{\dagger}$ Simulated results

The limitation of many PV-RO systems is membrane fouling which needs to be addressed with appropriate pre-treatment methods. To date such pre-treatment as well as long term system maintenance methodologies have not been fully explored. However, indications from the full scale surface water treatment applications literature indicates that ultrafiltration (UF) is superior in the prevention of fouling compared to microfiltration (MF) or more conventional methods like sand filtration. This is due to the presence of small colloidal materials, microorganisms and organic matter that cannot be removed effectively in other processes and hence deposits on the membrane material.

Further, reverse osmosis can be overkill for brackish water applications. If only small amounts of salt and hardness are to be removed from waters then nanofiltration (NF) can be a much more economic process for a remote community water supply [18]. If NF is an option for treatment then the production of highly concentrated brines can be reduced and, depending on the water quality, smart operation of the system may be able to prevent a concentrate disposal problem.

Further discussions with remote communities identified the need to design a simple and robust treatment system that can reliably disinfect the water and remove contaminants of concern such as arsenic or nitrates. Robust means a reduction in weak points of the system that are prone to cause breakdowns and failures, such as contaminant breakthrough or membrane fouling. Operational needs such as who is to operate the system, who pays for maintenance and who can fix minor problems and clean the membranes have been identified in those discussions. Those needs are significantly different to those of water treatment systems in urbanised areas. Cleaning, in particular, can be a difficult issue to handle as storage and handling of aggressive chemicals is a human and environmental safety concern in remote locations. Supply and disposal of such chemicals may be an additional challenge.

In terms of system performance and optimisation, the use of renewable energy challenges existing knowledge on membrane technology. The availability of a constant power source - and therefore pressure and flow - is usually taken for granted when designing membrane systems. Very little knowledge exists about the intermittent operation of membrane filtration plants and the impact on product water quality, fouling and membrane lifetime.

The concepts outlined above led to the development of a PV-RO unit, called ROSI (Reverse Osmosis Solar Installation), which is designed to deliver a production flow of 1 $000 \mathrm{~L}$ per day of clean drinking water from various ground or surface water sources to meet the demand of a small remote community of up to 200 people. The unit serves to conduct research into the design, operation \& maintenance and the socio-economic integration of small scale solar desalination systems.

\section{ROSI System Design}

The basic design concept for the reverse osmosis solar installation (ROSI) is to use photovoltaic, or solar, modules provide electric power to the pumps that produce the driving force for the hybrid membrane process. The system then delivers potable water from a variety of possible water sources, ranging from high turbidity surface waters to high salinity brackish water. For the various prototypes developed since 2001, an operating window is determined where the specific energy consumption (SEC) is acceptable and water quality produced meets drinking water guidelines.

A schematic of the ROSI system is shown in Figure 1 and a picture of the current system in Figure 2. The pre-treatment stage is an ultrafiltration (UF) membrane, which followed by the desalination stage, a reverse osmosis (RO) or nanofiltration (NF) membrane. The UF membrane removes most pathogens like bacteria as well as particles and some colloidal material (such as viruses or metal oxides). This protects the RO/NF membrane from excessive fouling, in particular biofouling, and hence reduces the cleaning frequency of these modules. The RO/NF membrane retains ionic species and organic material, decreasing salinity and a proportion of harmful trace contaminants (e.g. $\mathrm{F}, \mathrm{As}, \mathrm{B}, \mathrm{NO}_{3}, \mathrm{U}$ ) as well as dissolved organic matter. 
Schäfer, A.I. ; Broeckmann, A. ; Richards, B.S. (2005) Membranes and renewable energy - A new era of sustainable development for developing countries, Membrane Technology, Nov, 6-10. doi:10.1016/S0958-2118(05)70569-3

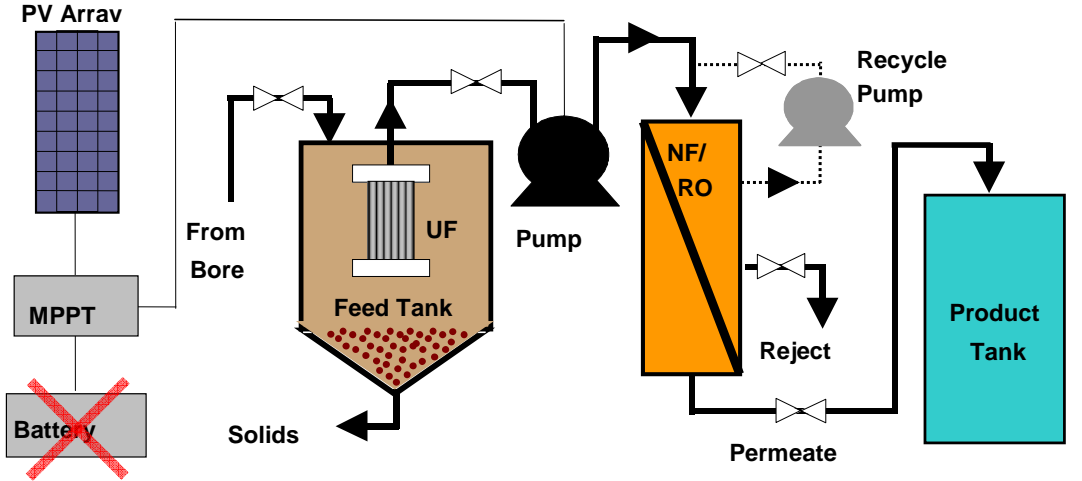

Figure 1: Schematic diagram of the membrane configuration of ROSI prototype III.

Further design requirements result from the projected application of the system in remote communities. The system has to be robust, almost maintenance free, modular in size to fit a wide range of water demands, and it must be able to perform stand-alone operation. Concerning the product quality, the system has to be capable of reliably removing salinity, trace contaminants as well as pathogens to meet the requirements for clean and healthy drinking water.

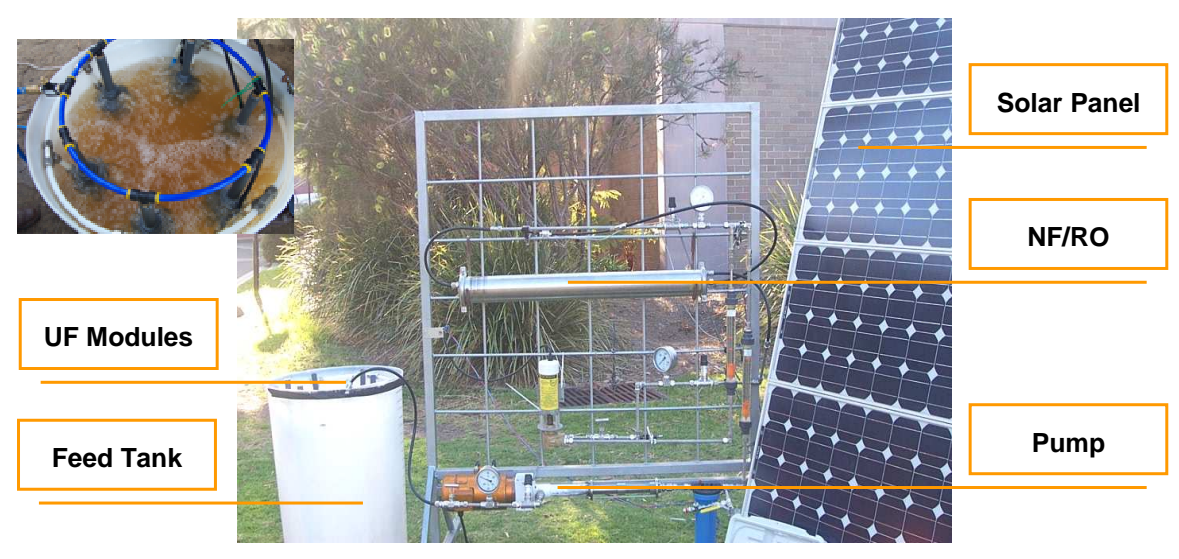

Figure 2: Picture of ROSI prototype III and submerged UF system in insert.

Pre-treatment UF membranes were selected because they remove suspended solids and colloidal materials completely and reliably without chemicals addition, in fact UF is an ideal pre-treatment method for RO [12]. Therefore, six submerged ultrafiltration modules,
$Z_{\text {Zenon }}{ }^{\mathrm{TM}}$ ZeeWeed 10 were selected for the pre-treatment process. The membranes have, according to the manufacturer, a nominal pore diameter of $0.4 \mu \mathrm{m}$, an effective membrane surface area of $0.93 \mathrm{~m}^{3}$ per module, an operating pressure range of $0.07-0.55$ bar, a typical permeate flow of $0.7 \mathrm{~L}$. $\mathrm{min}^{-1}$ and are operated in outside-in configuration. The UF is operated with a suction pressure by the high pressure pump.

The desalination RO/NF membranes are selected from various manufacturers with the intention to vary the membrane depending on the feedwater quality such as salinity and trace contaminant content. The design of a system fulfilling the remote area criteria [19] depends upon sacrificing high efficiency in terms of permeate flux, high recovery, salt rejection and operating pressure, with benefits of lower fouling incidence, low or no brine production and lower total energy input requirements [13]. In addition, the selection of an appropriate RO/NF membrane is feed water specific. Consequently, the choice of the $\mathrm{RO} / \mathrm{NF}$ membrane is crucial, but is water quality (and hence location) dependent. The testing of RO/NF modules is ongoing as promising new modules become available.

\section{System Performance and Ongoing Research}

The system optimisation consists of several stages. Firstly, the system performance is evaluated as a function of transmembrane pressure for a range of salt concentrations. Parameters describing the basic system performance are flux, retention and specific energy consumption (SEC). A set of sample results for one of the membranes tested (BW30, Dow, Filmtec) at a brackish salt concentration of $5 \mathrm{~g} / \mathrm{L}$ is shown in Figure 3 to Figure 5 as recovery, specific energy consumption and salt retention, respectively.

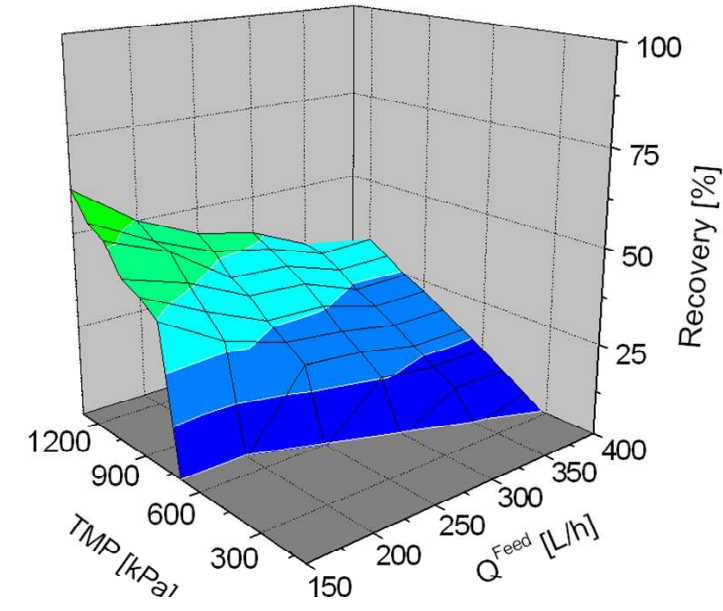

Figure 3: Recovery as a function of feed flow $\left(Q^{\mathrm{Feed}}\right)$ and transmembrane pressure (TMP) for a feed salt concentration of $5 \mathrm{~g} / \mathrm{L}$ (BW30 membrane). 
Recovery increased with increase in the driving force transmembrane pressure (TMP) and decreases with increasing feed flow at constant TMP. This relationship is inherent of membrane filtration and affected by the flux of a specific module, concentration polarization, as well as membrane fouling (which was not experienced in this study due to the nature of the experiments).

The specific energy consumption (SEC) is the amount of energy required to produce a certain amount of permeate (desalinated water). In general, SEC increases with increasing pressure and (in some cases) increasing feed flow due to the power consumption of the pump. At low pressure and high feed flow the SEC is very high as the recovery of the system is very low. At high flow and low pressure the SEC is very high due to the low recovery. SEC is membrane and feed water specific and affects the overall design of the system in terms of the area of solar panels required.
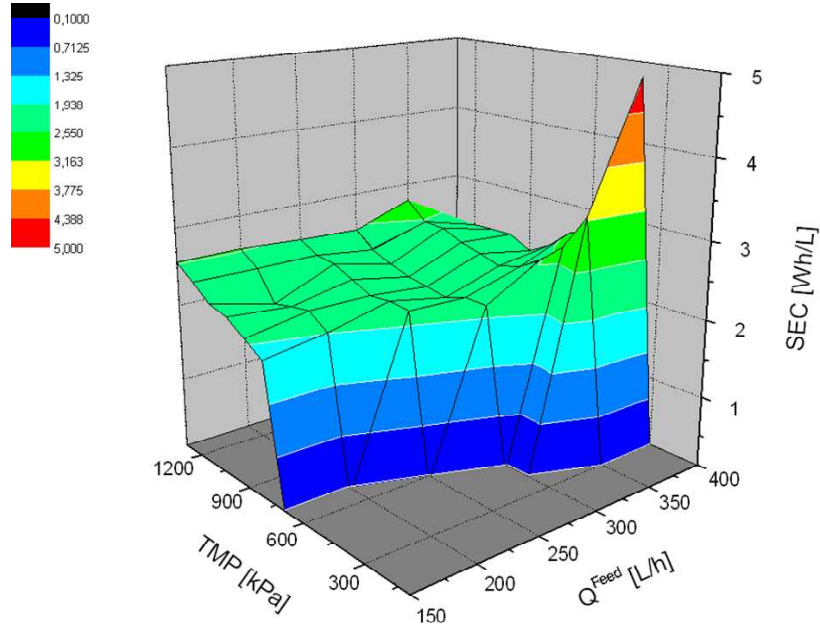

Figure 4: Specific energy consumption (SEC) versus feed flow $\left(Q^{\text {Feed }}\right)$ and transmembrane pressure (TMP) for a feed salt concentration of $5 \mathrm{~g} / \mathrm{L}$ (BW30 membrane).

Salt retention is limited by low pressure and low flow. In both cases concentration polarization and subsequent salt diffusion is the limiting phenomenon. At low feed flow the crossflow is too small to effectively control the boundary layer causing high salt concentration at the membrane surface, while at low pressure permeation of water is slow which allows salt to transport at a comparatively high rate across the membrane. This effect is very membrane specific and it is important to determine what variation in retention can be tolerated to achieve an adequate water quality over an average filtration period.

The investigations as a function of pressure and flow are important as the generated power will vary seasonally and daily with the sun's position in the sky, and also with local weather conditions (cloud cover). Since fluctuations in power will immediately affect pressure and flow, understanding both SEC and retention under varying conditions is therefore very important. In addition, system design according to manufacturer specifications (operating pressure and recovery) is not always a possibility and the determination of an appropriate operating window is being established as part of the research associated with this project. Outside this operating window the system needs to be operated in a bypass mode, however other low-energy functions can be performed during this period.
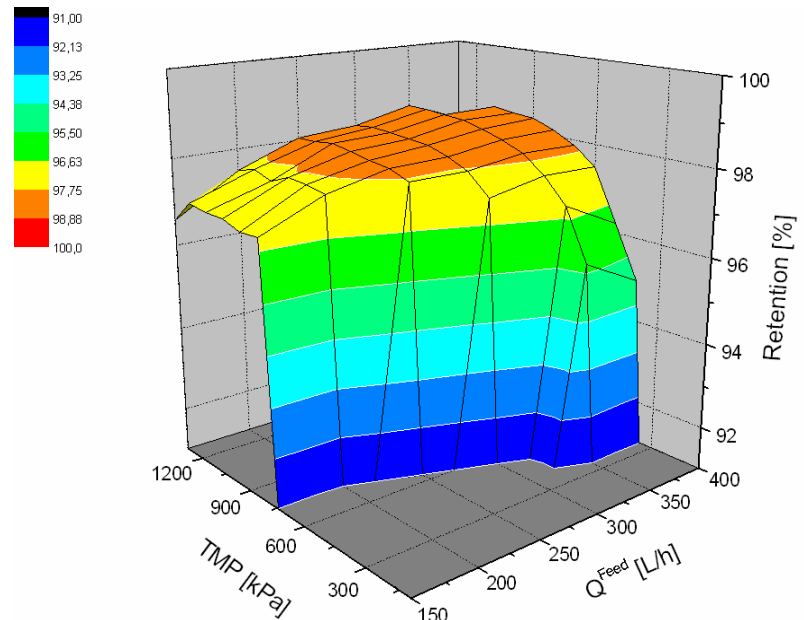

Figure 5: Salt retention versus feed flow $\left(Q^{\text {Feed }}\right)$ and transmembrane pressure (TMP) for a feed salt concentration of $5 \mathrm{~g} / \mathrm{L}$ (BW30 membrane).

The second stage of system testing is the retention of trace contaminants. Compounds of interest in remote communities are for example arsenic, boron, fluoride, uranium and nitrates amongst others. The retention of some of those compounds is speciation dependent and can be low with the more open membranes or in some cases even RO.

Trace contaminants are a critical problem in many regions of the world. Reliable removal of such compounds is unlikely to be possible with any other method than NF/RO because of those membranes being a physical barrier rather than a process that requires regeneration and hence a substantial amount of maintenance. However, membrane technology remains an 'advanced technology' and is energy intensive. It is thus important to couple such processes with renewable energy sources. The type of renewable energy depends on the system location and the most readily available renewable energy source.

\section{Conclusions and Future Needs}

Water and energy are global problems that no longer can be considered separately. Membrane technology is an important solution to global water quality and hence health problems as the characteristics are unique with regards to simultaneous disinfection, desalination and trace contaminant removal. The current political climate is such that 
Schäfer, A.I. ; Broeckmann, A. ; Richards, B.S. (2005) Membranes and renewable energy - A new era of sustainable development for developing countries, Membrane Technology, Nov, 6-10. doi:10.1016/S0958-2118(05)70569-3

advanced technology such as membranes are unaffordable for developing countries. Existing systems, in particular advanced technologies, often cannot be maintained in remote contexts and hence to not operate for extended periods which has given membrane technology a bad reputation in some circumstances. Hence further work is needed to integrate such treatment systems in a socially, economic and environmentally sustainable way. In consequence one then can demonstrate to global funding agencies and political organisations that desalination coupled with renewable energy is a very reliable and sustainable solution to the water needs of small communities, in developing countries or indigenous people in developed countries. The modular nature of both membranes and solar panels are a natural fit and there are very few, if any, technologies available that can reliably remove trace contaminants such as arsenic from contaminated water sources.

\section{Acknowledgements}

Project funding is provided by the Australian Research Council (ARC) under the Linkage scheme (project number LP0349322).

The project has been recognised with $2^{\text {nd }}$ prize in the category water at the Energy Globe Awards 2003 and received a Mondialogo Award in 2005. UNESCO and DaimlerChrysler are thanked in particular for their contribution to promoting sustainable engineering solutions for developing countries with their award for project implementation.

The many students who have worked on various aspects of this project since 2001 are acknowledged for their time and enthusiasm - and the reports that the project has planted a seed to carry on in this area.

\section{References}

1. Einav, R., K. Harussi, and D. Perry, The footprint of the desalination processes on the environment. Desalination, 2002. 152: p. 141-154.

2. Weber, W.J. Distributed optimal technology networks: An integrated concept for water reuse. in Integrated Concepts in Water Recycling - ICWR 2005. 2005. Wollongong Australia: UoW.

3. Hurlimann, A. and J. McKay. Community Attitudes to an Innovative Dual Water Supply System at Mawson Lakes South Australia. in OzWater 2003. 2003. Perth WA.

4. Law, I.B., Rouse Hill - Australia's first full scale domestic non-potable reuse application. Water Science \& Technology, 1996. 33(10-11): p. 71-78.

5. Hedberg, T., Attitudes to traditional and alternative sustainable sanitary systems. Wate Science \& Technology, 1999. 39(5): p. 9-16.

6. Thomas, J.S. and B. Durham, Integrated water resource management: looking at the whole picture. Desalination, 2003. 156: p. 21-28.

7. Malik, M.A.S., et al., Solar desalination, in Pergamon press. 1985

8. Joyce, A., et al., Small reverse osmosis units using PV systems for water purification in rural places. Desalination, 2001. 137: p. 39-44.

9. $\quad$ Cartwright, P.S., Membrane separation technologies - practical applications. 1998
10. Herold, D., et al., Small scale photovoltaic desalination for rural water supply demonstration plant in Gran Canaria. Renewable Energy, 1998. 14(1-4): p. 293-298.

11. Richards, B.S., C. Remy, and A.I. Schäfer, Sustainable drinking water production from brackish sources using photovoltaics. 2004

12. Côté, P., et al., A new immersed membrane for pretreatment to reverse osmosis. Desalination, 2001. 139: p. 229-236.

13. Robinson, R., G. Ho, and M. Kuruvilla, Development of a reliable low-cost reverse osmosis desalination unit for remote communities. Desalination, 1991. 86: p. 9-26.

14. Swinton, E.A., Developments in appropriate water treatments technologies. 1985

15. Thomson, M., M.S. Miranda, and D. Infield, A small-scale seawater reverse-osmosis system with excellent energy efficiency over a wide operating range. Desalination, 2002. 153: $\mathrm{p}$ 229-236.

16. Gotor, A.G., I.D.I.N. Pestana, and C.A. Espinoza, Optimization of RO desalination system powered by renewable energies. Desalination, 2003. 156: p. 351

17. Bouchekima, B., Solar desalination plant for small size use in arid areas of South Algeria for the production of drinking water. Desalination, 2003. 156: p. 353-354.

18. Schäfer, A.I., A.G. Fane, and T.D. Waite, Nanofiltration: Principles and Applications. 2005, Oxford: Elservier. 560

19. Rod Robinson, G.H.a.K.M., Development of a Reliable Low-Cost Reverse Osmosis Desalination Unit for Remote Communities. Desalination, 1991. 86: p. 9-26. 